\title{
Research on Personalized Construction of Vocational Guidance Work System in Colleges and Universities
}

\author{
Qianqian Li \\ College of Computer Science, Neijiang Normal University; Neijiang, Sichuan 641112 \\ liqianlau@163.com
}

Keywords: Higher vocational colleges; Work system; Problems; Measures

\begin{abstract}
Vocational guidance work is a highly specialized career currently of our country. This paper discussed the professional degree of China's vocational guidance in colleges and universities, and introduced a series of solution to enhance the professional degree, such as to construct the guidance agencies and team to promote the development of school.
\end{abstract}

\section{Introduction}

At present, the colleges in our country pay more and more attention to the vocational guidance work. In order to highlight this work, school takes all kinds of measures, such as offering the guidance courses, constructing the guidance agencies, etc. Owing to the lack of degree of specialization, the problem that low employment rate of college students arises. To solve it, we need to perfect the related organization and the system constantly.

\section{The Concrete Manifestation of the Lack of Professional Guidance in Colleges and Universities}

The Lack of Guidance of Specialized Agencies. It is mess when it comes to the name of agencies. Some colleges and universities treat it as an institution that don't mix together with other agencies; Also some colleges regard it as a small student body of work with the management and maintenance of students, which is a major drawback of the institution. [1] These colleges' emphasis differs in the problem concerns in the course of employment of graduates: some colleges pay attention to the ability that these graduates deal with emergencies and the specific solutions to the problems, while others focus on if these students can apply the knowledge of theoretical guidance that they have learned to the real life, which is another major drawback of the institution. In addition, there are a variety of problems existed in school environment: the serious shortage of teachers, lack of institutional venues, insufficiency of education funds, etc.

The Imperfect Guidance Team. As everyone knows, to open the occupation guidance course, we need a large number of occupation guidance teachers. But in terms of our guidance team, there is a big gap to fill in. The problem is that the guidance career is mainly managed by college counselors, and they are in charge of the daily management of students, basically, they have no professional knowledge background, which decide on the course performing practically no function. [2]

The Neglected Professional Assessment Evaluation. We use the evaluation software to test the students' emergency handling ability, personal hobbies, aspirations and employment objectives to help them to find a good job, and as much as possible to let them know themselves thoroughly. But most people do not get to the bottom, only seeing the surface results of the "evaluation". Towards the assessment evaluation, we not only need to "test", more to "review", from the western software, students can see their own evaluation results, but because of the lack of professional vocational assessment, resulting in some of their traits may not have been show up, so that they can't get a better understanding of their own ability ,personality and characteristics. 


\section{The Main Factors Leading to the Lack of Professional Guidance}

Theoretical Factors: The Foundation Is Weak, and the Localization Is not Enough. As of now, career guidance curriculum construction has been walking the path of other countries without their own innovation, so we still can't get good effect, this result is inevitable. [3] To change this situation, we must correct the defect of randomness and imitations existed in the occupation instruction, and regard it as the source of education to explore and study with the support of the theory of localization.

Cognitive Factors: The Concept is Old, and the Attention Is not Enough. Occupation guidance has been gradually recognized by our country, but many colleges and universities in our country still carry out the courses in the form of elective courses. [4] At present, the main purpose of many universities is to attract students to enter in, and the problem of employment becomes not essential. For the guidance teachers, they must have a good idea of education, not only can give graduates strong professional guidance ideal ,but can also help them to solve the problems during their school days.

Personnel Factors: Lack of Training and the Team Is not Stable. Vocational guidance teacher should not only help students with their study, but also guide them with employment knowledge .Because of its less importance in school; few teachers would like to join in the professional vocational guidance teacher training institutions, which result in the students can only get the shallow knowledge. [5]

Mostly, vocational guidance teachers are short-term or part-time teachers, the liquidity is very frequent, which directly lead to the instability of teaching quality. "It is never too late to learn" can also be used in the vocational guidance. Only accumulate the experience consistently in the process of learning, can we achieve the practical success.

Strategic Factors: The Form Is Single, and the Attraction Is not Strong. Single form mainly shows in the way of career guidance and the traditional form of teaching - teachers tell, and students just listen. ${ }^{[6]}$ Without the pleasure and something practical, can students learn it well? Therefore, in view of strategy, we should carry out a wide variety of teaching activities, strengthen the frequency of exchanges between teachers and students, so that lead teaching to achieve rich and colorful. [7]

\section{Measure to Strengthen the Construction of Professional Guidance System}

The work of occupation guidance is in the preliminary stage in our country currently, we need to strengthen the following several aspects of construction elements:

To Strengthen the Professional Guidance of the Organization. According to the importance of vocational guidance institutions towards the graduates, we should enhance all aspects of the organization, make it the foundation and key of employment, and the management, research and service as the important development prerequisite of guidance institutions, encourage students to strengthen the career planning, improve the innovation of guidance and the quality of service. [8]

To Strengthen the Construction of Professional Guidance Team. The professionalism of employment guidance means that staff engaged in students' employment guidance own their unique occupation requirements and conditions, added the special management system and training system, namely, the relevant employment guidance personnel should have the related knowledge structure, ability and quality, which requires they can not only be competent for the occupation development courses and do the follow - up survey towards graduate' employment and market research, but also be qualified to do the personalized guidance, and own the ability to engage in professional research. [9]

To Strengthen the Construction of Career Planning Guidance System. To help students to build up their own occupation goals, types and specific plans, that found an occupation career planning guidance system is important, thus the system should include in these following points: improve the students' occupation skill level with carrying out the occupation skill training; [10] test each student with the professional occupation personality test system by conducting the occupation 
International Conference on Education Technology and Training(Volume 2)[C].Hubei University of Technology, China:,2010:4.

[4] Fang Bian, Jixiang Zhu. Problems in University Career Guidance and Solutions [A]. Information Engineering Research Institute, USA. Proceedings of 2013 International Conference on Psychology, Management and Social Science(PMSS 2013) Volume 15[C].Information Engineering Research Institute,USA:,2013:5.

[5] Liping Guo, Zhenguang Wang. The Research on Employability Cultivation Mechanism of Polytechnic College in Hebei Province [A]. Information Engineering Research Institute, USA. Proceedings of 2012 International Conference on Education Reform and Management Innovation(ERMI 2012) Volume 1[C].Information Engineering Research Institute,USA:,2012:5.

[6] Huixin Wu. Exploration of the Mode of the Employment Guidance for the College Students under the Training of the Vocational Cultivation [A]. Information Engineering Research Institute, USA. Proceedings of 2015 4th International Conference on Social Sciences and Society (ICSSS 2015 V71)[C].Information Engineering Research Institute, USA:,2015:6.

[7] Lihua Zhao, Jixun Ma. Discussion on Professional Quality of Career Guidance Staff in Colleges and Universities [A]. Information Engineering Research Institute, USA. Proceedings of 2014 2nd International Conference on Social Science and Health (ICSSH 2014 V56)[C].Information Engineering Research Institute, USA:,2014:4.

[8] Shihai Zhua, Li Wang. Research and Practice of Open Career Education System for Undergraduates in Higher Vocational Colleges [A]. Hong Kong Education Society. Proceedings of 2012 2nd International Conference on Physical Education and Society Management (ICPESM 2012 V9)[C].Hong Kong Education Society:,2012:5.

[9] Xiujie Wu. Exploration and Thoughts on Instructional Supervision of Higher Vocational Education [A]. Hong Kong Education Society. Proceedings of 2013 International Conference on Economic, Business Management and Education Innovation(EBMEI 2013 V20)[C].Hong Kong Education Society:,2013:5.

[10] Yali Dai. Establishment and Implementation Approach of Full-course Developmental Employment Guidance Mode in Applied Undergraduate Colleges [A]. International Informatization and Engineering Associations 、Atlantis Press. Proceedings of 2014 2nd International Conference on Education Technology and Information System[C].International Informatization and Engineering Associations, Atlantis Press:, 2014:5.

[11] Zhang Cui-ying. The Question of Employment Guidance on the Whole Process in Higher Vocational College [A]. International Informatization and Engineering Associations, Atlantis Press. Proceedings of 2014 3rd International Conference on Science and Social Research[C].International Informatization and Engineering Associations, Atlantis Press:, 2014:4. 